\title{
CONCEPÇÕES DE LUDICIDADE NA EDUCAÇÃO INFANTIL ENUNCIADOS EM PERIÓDICOS NO PERÍODO DE 2015-2019
}

\author{
CONCEPTIONS OF CHILDHOOD EDUCATION PLAYED IN JOURNALS IN THE 2015- \\ 2019 PERIOD
}

Jamyla de Aguiar Frota ${ }^{1}$

RESUMO: Este Trabalho de Conclusão de Curso (TCC) consiste em estudos sobre concepções de ludicidade trabalhados na Educação Infantil, enunciados em artigos publicados em periódicos entre os anos 2015 e 2019. Tem como objetivo geral investigar os enunciados sobre ludicidade na educação infantil nos últimos 5 anos. A pesquisa trata-se de um estudo de caráter qualitativo do tipo pesquisa bibliográfica. Os artigos foram selecionados na plataforma de Periódicos da CAPES, por meio de processo de leituras e análises. A cada dia cresce este resgate dos jogos e brincadeiras como ações de cunho pedagógico, auxiliando de forma contextualizada no repasse de conteúdos e fortalecendo os valores e princípios nos alunos como solidariedade, cooperação mútua e respeito entre os colegas, incentivando competições saudáveis que tem por meta formar pessoas que aprendam em um ambiente mais criativo e propício à aprendizagem. Não é uma tarefa fácil conciliar os momentos lúdicos sem que se tornem vazios de significação para os alunos. São ações que devem ser muito bem planejadas para que não virem apenas momentos de lazer, desconectados do ato de aprender. Este desafio colocado aos professores, quando bem estruturado, traz benefícios positivos e uma forma mais libertadora de educação.

Palavras-chave: Jogos e brincadeiras. Atividades lúdicas. Processo Ensino-Aprendizagem.

ABSTRACT : This Course Conclusion Paper (TCC) consists of studies on concepts of playfulness worked in Early Childhood Education, spelled out in articles published in journals between the years 2015 and 2019. Its general objective is to investigate the statements about playfulness in early childhood education in the last 5 years. The research is a qualitative study of the type bibliographic research. The articles were selected on the CAPES Periodicals platform, through a reading process and their analysis. This rescue of games and games as pedagogical actions grows every day, helping in a contextualized way in the transfer of content and strengthening the values and principles of students such as solidarity, mutual cooperation and respect among colleagues, encouraging healthy competitions that have as their goal train people who learn in a more creative and conducive environment for learning. It is not an easy task to reconcile playful moments without becoming meaningless for students. These are actions that must be carefully planned so that they do not come only as leisure moments, disconnected from the act of learning. This challenge placed on teachers, when well structured, brings positive benefits and a more liberating form of education.

Keywords: Games and games. Playful activities. Teaching-Learning Process.

${ }^{1}$ Graduada pelo Curso de Pedagogia pela Faculdade Ieducare -FIED. E-mail: jamyla_cdd@yahoo.com.br 


\section{INTRODUÇÃO}

As atividades lúdicas sempre fizeram parte do cotidiano da criança. A criança desde muito pequena é inserida no mundo das brincadeiras, sendo algo comum no seu dia a dia. $\mathrm{O}$ brincar se torna um momento prazeroso podendo propiciar a aprendizagem. Nesse contexto, as atividades lúdicas devem estar vinculadas a um propósito pedagógico cheio de intencionalidade.

O brincar e o jogar são atividades indispensáveis para a criança favorecendo a saúde, a socialização, seu cognitivo e seu emocional, elas sempre estiveram presentes na história desde a antiguidade até os tempos atuais. Através dos jogos e brincadeiras, a criança desenvolve a linguagem, o pensamento, a socialização, a autoestima, a autonomia, e a imaginação. (ALMEIDA, 2013).

- O lúdico se faz presente a acrescentar um ingrediente indispensável no relacionamento das pessoas, principalmente no mundo infantil, possibilitando que a criatividade aflore. À medida que a criança interage com os jogos e brincadeiras e com outras pessoas, construirá relações e conhecimentos a respeito do mundo que a rodeia. A escola, a família, em parceria, deve favorecer uma ação de liberdade para a criança, uma sociabilização que se dará gradativamente, através das relações que ela irá estabelecer com seus colegas, professores e outras pessoas (ROGERS, 2015)

A criança deve sentir-se livre nos momentos de brincadeiras, pois é nesses momentos que ela exprime seus sentimentos e desejos. Suas diferenças e experiências individuais devem, principalmente na escola, ter um espaço relevante sendo respeitadas nas relações com o adulto e com outras crianças. Brincando em grupo as crianças envolvem-se em uma situação imaginária onde cada um poderá exercer papéis diversos aos de sua realidade, além de que, estarão necessariamente submetidas a regras de comportamento e atitude.

A ludicidade na Educação Infantil como fator que favorece o desenvolvimento Infantil é de suma importância. $O$ interesse por essa temática surgiu através de uma atuação em uma sala de aula de Educação Infantil em uma escola pública do município de TianguáCeará, na qual foi aplicado um projeto desenvolvido na graduação do curso de Pedagogia. 
Nesta ocasião foi observada a relevância do ato de brincar para o desenvolvimento das crianças.

Brincar é a forma mais perfeita para perceber a criança e estimular o que ela precisa para aprender e se desenvolver. Diante desse entendimento surgiram as seguintes inquietações: Qual a importância dos jogos e brincadeiras na educação infantil para o processo formativo geral das crianças? $O$ que dizem os enunciados de periódicos sobre ludicidade na educação infantil dos últimos 5 anos?

Brincar reforça laços afetivos. Todas as crianças gostam de brincar com os professores, pais, irmãos, e avós. E a participação do adulto na brincadeira com a criança é muito importante, pois favorece o nível de interesse pelo enriquecimento que a brincadeira proporciona, e contribui para o ensino-aprendizagem. Segundo a BNCC (2018), o brincar é um dos seis direitos de aprendizagem na Educação Infantil, a criança deverá brincar cotidianamente, de diversas formas e em diferentes ambientes, com diferentes parceiros sejam adultos ou crianças. E são através das brincadeiras que ela ampliará seus conhecimentos, sua imaginação, sua criatividade, suas experiências emocionais, cognitivas, físicas, relacionais e sociais.

A metodologia utilizada neste artigo fez uso da pesquisa bibliográfica, que permitiu trazer discussões, ideias e opiniões dos autores selecionados no Portal de periódicos da CAPES. O objetivo geral deste estudo é investigar os enunciados sobre ludicidade na educação infantil nos últimos 5 anos, entre os anos 2015 e 2019. Os Objetivos específicos buscaram: identificar as concepções de ludicidade anunciadas nos periódicos; identificar os discursos sobre ludicidade na Educação Infantil; compreender a importância dos jogos na pratica pedagógicas apresentados nos periódicos.

Este estudo compõe uma pesquisa qualitativa e bibliográfica, e estão divididos em três sessões. A primeira apresenta uma revisão de literatura, com aspectos relevantes sobre a ludicidade na Educação Infantil e jogos e brincadeiras para o desenvolvimento das crianças. A segunda apresenta toda a concepção metodológica e os procedimentos técnicos e operacionais empregados na escolha do material analisado e na terceira, e ultima, abordo a análise dos conteúdos extraídos dos artigos tendo como proposta a ludicidade na Educação Infantil. 


\section{REFERENCIAL TEÓRICO}

\section{I O Lúdico na Educação Infantil}

A ludicidade é algo que faz parte da rotina da Educação Infantil, e está muito presente neste ambiente, pois favorece a aprendizagem do público infantil no geral. É através dos jogos e brincadeiras que as crianças conseguem assimilar melhor todo o conteúdo trabalhado em sala de aula, permitindo que o trabalho pedagógico possibilite a produção do conhecimento, aprendizagem e desenvolvimento. (ANTUNES, 2014). Independentemente de época, cultura e classe social, os jogos e brinquedos fazem parte da vida da criança, pois elas vivem em um mundo de fantasia, encantamento, alegria, e sonhos onde a realidade e o faz-de-conta se confundem.

A criança é levada pelo encantamento presente através da ludicidade, fazendo com que a criança entre em mundo magico cheio de imaginação, em um lugar só dela, onde cria e recria tudo a sua volta, é nesse criar e recriar que a mesma vai assimilando e aprendendo. Por isso a ludicidade deve ser vista como um instrumento de aprendizagem e os professores devem ter consciência disso, já que a ludicidade vem paulatinamente sendo relegada apenas ao passatempo vazio, desvinculado do aprender.

Resgatar a simbiose entre o brincar e os conteúdos programáticos, bem como fomentar, nos alunos, o interesse pelo lúdico e muitas outras questões sobre a relação do brincar com a aprendizagem e o desenvolvimento da criança é muito importante, pois fortalece a intencionalidade do lúdico na prática pedagógica. Para Velasco (2015, p.84):

\footnotetext{
O lúdico tem sua origem na palavra latina "ludus" que quer dizer "jogo". Se achasse confinado à sua origem, o termo lúdico estaria se referindo apenas ao jogar, ao brincar, ao movimento espontâneo. No entanto, o lúdico passou a ser reconhecido como traço essencial de psicofisiologia do comportamento humano. De modo geral, a sua definição deixou de ser o simples sinônimo de jogo. Neste contexto, as implicações da necessidade lúdica extrapolaram as demarcações do brincar espontâneo.
}

O lúdico é essencial para o desenvolvimento humano, ele ultrapassa as dimensões de somente jogar. A ludicidade está presente em todo ambiente, isso dependerá do olhar de quem a ver. Para brincar e jogar não precisa de muito esforço, pois é algo quem já é natural para ela. 
A ludicidade é tão importante para a criança, pois à criança se expressa através do lúdico, pois para ela a ludicidade faz sentido. É nas brincadeiras que ela aprende a se relacionar com o outro e a entender o mundo a sua volta. Brincando a criança tem contato direto por meio da interação com o objetivo da ludicidade. E nessa interação, segundo Ribeiro (2016, p. 89):

O lúdico possibilita o estudo da relação da criança com o mundo externo, integrando estudos específicos sobre a importância do lúdico na formação da personalidade. Através da atividade lúdica e do jogo, a criança forma conceitos, seleciona ideias, estabelece relações lógicas, integra percepções, faz estimativas compatíveis com o crescimento físico e desenvolvimento e, o que é mais importante, vai se socializando.

Segundo Antunes (2014), várias são as razões que levam os educadores a recorrer às atividades lúdicas e a utilizá-las como um recurso no processo de ensino-aprendizagem, como incentivo à tendência natural que o ser humano tem de expressar sua ludicidade, independentemente da idade, cada fase tem seus critérios e suas estratégias para que essa ludicidade atenda ás exigências de uma sociedade melhor onde o conhecimento é fundamental. Para isso, somam-se dois fatores: o prazer advindo das atividades lúdicas e o progresso através do esforço espontâneo e individual.

O brincar faz parte do processo de ensino-aprendizagem dos alunos e algo muito importante que deve ser trabalho na sala de aula, o ato de brincar, nas escolas, se configura uma proposta pedagógica que incorpora o lúdico como eixo do desenvolvimento infantil. Desta maneira, a aproximação com a realidade do brincar proporciona a compreensão acerca da inexistência de espaço para o desenvolvimento cultural dos alunos.

\section{BRINCADEIRAS COMO FERRAMENTAS DO LÚDICO PARA O DESENVOLVIMENTO DA CRIANÇA}

O lúdico é uma ferramenta muito importante para o desenvolvimento da criança desde os primeiros anos de vida, a criança para se desenvolver bem necessita brincar, imaginar, jogar, inventar e criar. A ludicidade faz parte do universo infantil e só tem a agregar na prática pedagógica, pois permite que a criança aprenda brincando. Esse brincar mediado pelo professor se torna uma ferramenta maravilhosa para auxiliar no desenvolvimento do educando na Educação Infantil. Segundo Almeida (2013, p.142) 
Através dos jogos e brincadeiras, o educando encontra apoio para superar suas dificuldades de aprendizagem, melhorando o seu relacionamento com o mundo. Os professores precisam estar cientes de que a brincadeira é necessária e que traz enormes contribuições para o desenvolvimento da habilidade de aprender e pensar.

As brincadeiras e jogos são fundamentais no processo de aprendizagem, pois é através deles que muitos alunos conseguem aprender e se desenvolver melhor. Os professores devem usar esses recursos frequentemente principalmente na Educação Infantil, pois permite que a criança ao ter contato com os jogos ou com as brincadeiras aprendam de forma prazerosa. A criança é protagonista de sua própria aprendizagem. Conforme as DCNEI (2009) propõem que os eixos estruturantes das praticas pedagógicas da Educação Infantil deve estar organizada por eixos de interações e brincadeiras. E é por meios das interações e brincadeiras que a criança criará meios de se desenvolver progressivamente nas dimensões físicas, emocionais, cognitivas, sociais e relacionais.

Propõe também seis direitos de aprendizagem e desenvolvimento na Educação Infantil, são eles: conviver, participar, explorar, expressar, conhecer-se e brincar. Ao brincar e jogar a criança exercita todos estes direitos que são ferramentas essenciais para o seu desenvolvimento.

Em todos os tempos, para todos os povos, os brinquedos evocam as mais sublimes lembranças. São objetos mágicos, que vão passando de geração em geração, com um incrível poder de encantar crianças e adultos. Segundo SOLÈ, (2013 p. 126) “[...] diferindo do jogo, o brinquedo supõe uma relação intima com a criança e uma indeterminação quanto ao uso, ou seja, a ausência de um sistema de regras que organizam sua utilização". Para Winnicott (2016, p. 87)

O brinquedo contém sempre uma referência ao tempo de infância do adulto com representações vinculadas pela memória e imaginações. O vocábulo "brinquedo" não pode ser reduzido à pluralidade de sentidos do jogo, pois conota a criança e tem uma dimensão material, cultural e técnica. Enquanto objeto, é sempre suporte de brincadeira.

O brinquedo é a oportunidade de desenvolvimento. Brincando, a criança experimenta, descobre, inventa, aprende e confere habilidades. O brincar é de grande relevância para a criança, permite que ela desenvolva a sua autoconfiança, sua curiosidade, 
concentração, atenção e autonomia. O brinquedo traduz o real para a realidade infantil, é no ato de brincar que a criança manifesta seus desejos e sentimentos.

Brincando, a criança desenvolve sua cognição, estimulando toda a sua capacidade de aprender algo novo. E é na qualidade de oportunidade que estão sendo oferecidas à criança através de brincadeiras e de brinquedos garante que suas potencialidades e sua afetividade se harmonizem. Para Oliveira (2016, p. 65) pode se dizer que:

O prazer não pode ser considerado a característica definidora do brinquedo, como muitos pensam. O brinquedo na verdade, preenche necessidades, entendendo-se estas necessidades como motivos que impelem a criança à ação. São exatamente estas necessidades que fazem a criança avançar em seu desenvolvimento.

O ato de brincar é algo que faz parte do dia a dia da criança, é nestes momentos que a criança aguça toda a sua curiosidade transformando-a em ação, favorecendo o seu desenvolvimento. Brincando a criança estimula todo o seu corpo favorecendo até mesmo a prática de atividades físicas, além de favorecer as relações interpessoais com outras crianças.

“A brincadeira transmitida à criança através de seus próprios familiares, de forma expressiva, de uma geração a outra, ou pode ser aprendida pela criança de forma espontânea”

(VELASCO, 2015, p.57). É a ação que a criança desempenha ao concretizar as regras de jogo, ao mergulhar na ação lúdica. Pode-se dizer que é o lúdico em ação.

Os jogos e brincadeiras são excelentes oportunidades de mediação entre o prazer e o conhecimento historicamente constituído, já que o lúdico é eminentemente cultural. Por meio da ótica de Piaget (1967, p.44) pode-se notar que "a concepção dos jogos não é apenas uma forma de desafogo ou entretenimento para gastar energias das pessoas, mas meios que contribuirão para o enriquecimento do desenvolvimento cognitivo”. Para ROGERS (2015), o objetivo dos jogos é auxiliar o processo de aquisição de conhecimento do educando a partir de recursos proporcionado pelo jogo de forma a mostrar uma prática pautada nas regras presentes nos jogos, para que os educadores possam dinamizar o ensino.

\section{JOGOS COMO RECURSOS DA LUDICIDADE}

Os jogos estão presentes dentro do conceito de ludicidade, e se tornam ferramentas importantes dentro do processo de ensino-aprendizagem, pois favorece a assimilação de conhecimentos. Os jogos e as brincadeiras dão as crianças sentido ao seu mundo interior. 
Dessa forma, as brincadeiras afloram as suas descobertas, tornando a aprendizagem significativa e prazerosa.

Os alunos em sala de aula poderão estar vivenciando de maneira lúdica, através da psicomotricidade e dos jogos novas maneiras de aquisição de conhecimentos, aprendendo de forma diferenciada. Segundo Velasco (2015, p.78):

\footnotetext{
Brincando, a criança desenvolve suas capacidades físicas, verbais ou intelectuais. Quando a criança não brinca, ela deixa de estimular, e até mesmo de desenvolver as capacidades inatas podendo vir a ser um adulto inseguro, medroso e agressivo. Já quando brinca à vontade tem maiores possibilidades de se tornar um adulto equilibrado, consciente e afetuoso.
}

Brincando a criança terá a possibilidade de se desenvolver melhor, o brincar estimula a criança como um todo. Dessa forma, por meio dos jogos e brincadeiras o educando encontra apoio para superar suas dificuldades de aprendizagem melhorando o relacionamento com o mundo à sua volta. É uma situação que destaca o potencial simbólico das crianças e é um fator para a aprendizagem durante toda trajetória da Educação Infantil, mas feita de maneira eficácia, com trabalho, dedicação e empenho dos professores e não de forma inteiramente aleatória e sem nexo. E sem a interação do professor será totalmente previsível de acontecer (BROUGERE, 2013).

Nesse sentido, os jogos e as brincadeiras não devem ser levados como algo sem importância, mas como algo que facilita e possibilita o processo de aprendizagem, por isso as atividades lúdicas executadas em sala de aula devem ser prazerosas fortalecendo o aprendizado das crianças que compõem a Educação Infantil, juntamente com a interação do professor. Além disso, os jogos e as brincadeiras não devem se configurar apenas como um dos meios para fortalecer o aprendizado e não um fim.

Segundo Kishimoto (2014) o uso dos jogos para fins pedagógicos não é uma inovação. Mas um recurso que possibilita repassar os conteúdos programáticos de forma lúdica. Geralmente os jogos e brincadeiras surgiram de maneira espontânea, mas tem além da função de manter as tradições, a de manter viva a cultura na qual se originou. E complementa Oliveira (2016, p. I6o) “durante a percepção dos objetivos de um jogo ou brincadeira, as crianças ampliam sua visão de mundo e exercita sua imaginação, instigando sua imaginação e aumentando seu poder cognitivo". 
O lúdico é uma das essências da vida humana que instaura e constitui novas formas de viver a vida social, marcada pela exaltação dos sentidos e das emoções misturando alegria, sentimentos e sensações. RCNEI (1998) salienta que para brincar é preciso apropriar-se de elementos da realidade imediata de tal forma a atribuir-lhes novos significados. Essa peculiaridade da brincadeira ocorre por meio da articulação entre a imaginação e a imitação da realidade. Toda brincadeira é uma imitação transformada, no plano das emoções e das ideias, de uma realidade anteriormente vivenciada.

É pertinente lembrar que os Referenciais curriculares Nacionais para a Educação Infantil afirmam que o aprendizado das crianças acontece por meio de imitações e imaginação, porém valem ressaltar que o professor deve estimular a criatividade por meio do manuseio e manipulação dos objetos, jogos educativos e da imaginação que cada criança carrega seus conhecimentos prévios.

É durante as brincadeiras, quando efetuadas eficazmente, que as crianças da Educação Infantil aprendem a contar, ler, escrever e dão vida aos serem inanimados como os jogos educativos por exemplo. É durante as brincadeiras que as crianças fortalecem o espírito e os laços de afetividade, trocar informações e a vivenciá-las nos mais diferentes aspectos.

\section{METODOLOGIA}

A metodologia deste artigo se enquadra em uma pesquisa bibliográfica, pois permite averiguar o que já foi estudado sobre o objeto em estudo. Conforme Marconi Lakatos (2019) “a pesquisa bibliográfica não é mera repetição do que já foi dito ou escrito sobre certo assunto, visto que propicia o exame de um tema sobre um novo enfoque ou abordagem, chegando à conclusão inovadora”.

Assim como cita Marconi Lakatos (2019) Através da pesquisa bibliográfica é possível ser realizada várias opiniões sobre determinado assunto, sempre adquirido novos conhecimentos e resultados acerca do problema abordado, podendo assim ser compreendido de várias maneiras.

Quanto à abordagem do tema é qualitativa, pois busca expor uma realidade que não se concentra nem se limita a algo ou alguém, mas procura colocar questões gerais que possam servir de base a outros trabalhos que proponham temáticas semelhantes. 


\begin{abstract}
Normalmente são implementadas técnicas de coleta, codificação e análise de dados, que têm como meta gerar resultados a partir dos significados dos fenômenos estudados, sem a manifestação de preocupações com a frequência com que os fenômenos se repetem no contexto do estudo. Não há uma preocupação com medidas, quantificações ou técnicas estatísticas de qualquer natureza. Busca-se compreender, com base em dados qualificáveis, a realidade de determinados fenômenos, a partir da percepção dos diversos atores sociais (MINAYO, 2017, p. 32)
\end{abstract}

Quanto à obtenção de dados seguiu-se estas orientações e foi proposto a definição os critérios das publicações analisadas, foram estes:

a) Deveriam ser elas encontradas na plataforma de busca Portal de periódicos da CAPES;

b) Deveriam ser elas encontradas com as palavras-chave: ludicidade AND Educação Infantil. Estas foram pedidas no título das publicações;

c) Deveriam ser elas artigos publicados nos últimos 5 anos;

Definidos tais critérios, após leitura dos títulos e resumos foram encontrados 4 produções. Assim, foram obtidos a quantidade de 4 artigos a serem relidos e analisados, estes estão apresentados no abaixo.

Quadro I- Produções analisadas.

\begin{tabular}{|c|c|}
\hline Qtde & Artigo \\
\hline I & $\begin{array}{l}\text { Eliete da Silva Cambraia, Nilcel Léa Lobato, Rômulo Pereira Nascimento. A } \\
\text { ludicidade na alfabetização matemática no âmbito da Educação Infantil (2018). } \\
\text { Revista de Educação matemática, Dourados - MS - Número v.I pp. 76-91, (2008). }\end{array}$ \\
\hline 2 & $\begin{array}{l}\text { Simone Ribeiro Oliosi. A ludicidade no contexto das práticas pedagógicas na Educação } \\
\text { Infantil de o a } 3 \text { anos (2016). Revista Even. Pedagogo. Número Regular: Experiência } \\
\text { em Educação do Campo: perspectivas e práticas pedagógicas, Sinop, v.7, n. } 3 \text { (2o.ed.), } \\
\text { p. 1307-1320, ago./dez. 2016. }\end{array}$ \\
\hline 3 & $\begin{array}{l}\text { Daniel Cortes Beretta, Juciene Silva Oliveira, Daniela Costa Vilela. A extensão } \\
\text { universitária e a ludicidade na Educação Infantil contra crueldade animal e violência } \\
\text { interpessoal (2016). Revista Brasileira de Extensão Universitária, v.7, n.2, p. I39-I44 } \\
\text { jul./dez. 2016. Centro Universitário de Mineiros (UNIFIMES), Brasil }\end{array}$ \\
\hline 4 & $\begin{array}{l}\text { Denise Watanabe, Tony Aparecido Moreira, José Milton de Lima, Márcia Regina } \\
\text { Canhoto de Lima. A interatividade como ferramenta da ludicidade em busca de } \\
\text { caminhos e sentidos na Educação Infantil (2016). Revista Colloquium Humanarum, } \\
\text { Presidente Prudente, v.13, n.3, p.18-27 jul./set 2016. }\end{array}$ \\
\hline
\end{tabular}

Fonte: A pesquisadora. 


\section{ANÁlisE E DISCUSSÕES}

Para a elaboração deste trabalho foram selecionados alguns artigos que tiveram como principal critério de escolha a abordagem da temática a qual o trabalho de pesquisa se dedica, além de ter um conteúdo consistente, abrangente e que concorresse para a consecução exitosa do trabalho. Entre os que foram revisados, foram selecionados 4 (quatro), a saber: A ludicidade na alfabetização matemática no âmbito da Educação Infantil (2018), A ludicidade no contexto das práticas pedagógicas na Educação Infantil de o a 3 anos (2016), A extensão universitária e a ludicidade na Educação Infantil contra crueldade animal e violência interpessoal (2016) e A interatividade como ferramenta da ludicidade em busca de caminhos e sentidos na Educação Infantil (2016).

Os tópicos a seguir discorrem sobre os resultados e discussões da pesquisa. Tendo em vista os objetivos com este estudo, optou-se por apresentar tópicos específicos em que, no primeiro foram tratados das concepções de ludicidade na Educação Infantil e, no segundo, apresentados os sentidos da ludicidade na Educação Infantil e, o terceiro mostra a importância das brincadeiras nas práticas pedagógicas para o processo de ensino e aprendizado na Educação Infantil.

\section{I CONCEPÇÕES DE LUDICzDADE NA EDUCAÇÃO INFANTIL}

No quadro 2: Será exposto o tipo do texto e a concepção da ludicidade na Educação Infantil, encontradas em cada um deles.

Quadro 2- Concepções de ludicidade.

\begin{tabular}{|l|l|l|}
\hline Autor & $\begin{array}{l}\text { Tipo de } \\
\text { texto }\end{array}$ & \multicolumn{1}{|c|}{ Concepções de ludicidade } \\
\hline $\begin{array}{l}\text { Cambraia, } \\
\text { Lobato, } \\
\text { (2018) }\end{array}$ & Empírico & $\begin{array}{l}\text { A ludicidade é uma forma didática pedagógica estudada por } \\
\text { muitos pesquisadores que visam aprimorar o ato das } \\
\text { descobertas realizadas pelas crianças através de suas } \\
\text { interações e trocas de experiência. (p.73) }\end{array}$ \\
\hline $\begin{array}{l}\text { Oliosi } \\
(2016)\end{array}$ & Empírico & $\begin{array}{l}\text { A ludicidade é livre de pressões ou avaliações, ou seja, não } \\
\text { deve ser um processo forçado. As crianças são avaliadas dia a } \\
\text { dia pelo seu desenvolvimento e então o professor pode } \\
\text { enriquecer estes momentos com novas experiências pensadas } \\
\text { em cada criança, visto que cada uma se expressa de uma } \\
\text { maneira e, interage com suas peculiaridades. (p.I3I2) }\end{array}$ \\
\hline
\end{tabular}




\begin{tabular}{|l|l|l|}
\hline $\begin{array}{l}\text { Beretta, } \\
\text { Oliveira } \\
\text { Vilela } \\
(2016)\end{array}$ & Empírico & $\begin{array}{l}\text { A ludicidade é uma genuína expressão da emoção através das } \\
\text { brincadeiras. }\end{array}$ \\
\hline $\begin{array}{l}\text { Watanabe, } \\
\text { Moreira, } \\
\text { Lima \& } \\
\text { Lima } \\
(2016)\end{array}$ & Empírico & Não encontrado \\
\hline
\end{tabular}

Fonte: A pesquisadora.

Nas produções de Cambraia, Lobato, Nascimento (2018), Oliosi (2016), Beretta, Oliveira Vilela (2016), Watanabe, Moreira, Lima \& Lima (2016) foram utilizadas pesquisas empíricas, com abordagem qualitativa. As fundamentações teóricas encontradas no trabalho Watanabe, Moreira, Lima \& Lima (2016) para fundamenta o conceito de ludicidade foram os teóricos Piaget (2007), Vigostsky (2000), Dallanona; Mendes (2004). Na produção de Oliosi (20r6) Diretrizes da Educação Infantil e a Tizuko Morchida Kishimoto. Em Beretta, Oliveira Vilela (2016) e em Watanabe, Moreira, Lima \& Lima (2016), mesmo apresentando nos títulos dos trabalhos a palavra ludicidade, no corpo dos textos não foram encontrados os referenciais teóricos sobre ludicidade. Sendo que no último identificamos que a produção se utilizou do conceito de interatividade.

Segundo os autores o lúdico pode ser um instrumento indispensável na aprendizagem, no desenvolvimento e na vida das crianças, tornando evidente que os professores e futuros professores devem e precisam tomar consciência desta realidade, saber se os professores atuantes têm conhecimento de alguns conceitos, como o lúdico e a brinquedoteca e muitas outras questões sobre a relação do brincar com a aprendizagem e o desenvolvimento da criança.

É através das brincadeiras que a criança representa o discurso externo e o interioriza, construindo seu próprio pensamento. $\mathrm{O}$ adulto transmite à criança certa forma de ver as coisas (OLIVEIRA, 2016). Quando apresentamos várias coisas ao mesmo tempo, ou então por tempo insuficiente ou excessivo, estamos desestimulando o estabelecimento de uma atitude de observação.

Caso se queira que a criança aprenda a observar, ela tem que saber realmente o que olha e observa, tem-se que escolher o momento certo para apresentar-lhe o objeto, motivá- 
la e dar-lhe tempo suficiente para que sua percepção penetre no objeto. Tem-se também que respeitar o seu interesse.

Insistir quando a criança já está cansada é propiciar o aparecimento de certas reações negativas. Aprender a ver é o primeiro passo para o processo de descoberta. É o adulto quem proporciona oportunidades para à criança ver coisas interessantes, mas é indispensável que respeitemos o momento de descoberta da criança para que ela possa desenvolver a sua capacidade de concentração.

Quanto mais interessante à brincadeira para as crianças, mais rico se torna o aprendizado no ato de brincar. $\mathrm{O}$ brincar enquanto promotor da capacidade e potencialidade da criança, deve ocupar um lugar especial na prática pedagógica, tendo como espaço privilegiado, a sala de aula. A brincadeira e o jogo precisam vir à Escola. Muito pode ser trabalhado a partir de jogos e brincadeiras. Contar, ouvir histórias, dramatizar, jogar com regras, desenhar entre outras atividades, constituem meios prazerosos de aprendizagem.

\subsection{JOGOS NA EDUCAÇÃO INFANTIL}

A educação lúdica sempre esteve presente em todas as épocas entre os povos e estudiosos, sendo de grande importância no desenvolvimento do ser humano na educação infantil e na sociedade. Os jogos e brinquedos sempre estiveram presentes no ser humano desde a antiguidade, mas nos dias de hoje visão sobre o lúdico é diferente. Implicam-se o seu uso e em diferentes estratégias em torno da pratica no cotidiano.

Foram realizados nesta pesquisa leituras nos artigos encontrados no portal de periódicos da CAPES, na qual os mesmos têm como objetivo mostrar a importância dos jogos na Educação Infantil, na qual vem sendo destacado no quadro 3.

Quadro 3- Jogos na Educação Infantil

\begin{tabular}{|l|l|}
\hline Autor & Artigo \\
\hline $\begin{array}{l}\text { Cambraia, } \\
\text { Lobato, } \\
\text { Nascimento } \\
\text { (2018) }\end{array}$ & $\begin{array}{l}\text { Sendo assim, jogo em si, não deve exigir sempre resultado positivo } \\
\text { da criança, ele tem que causar prazer, assim como o ato de brincar, se } \\
\text { e tedio, esse jogo não está alcançando aprendizagem pedagógica. } \\
\text { (p.86) }\end{array}$ \\
\hline
\end{tabular}




\begin{tabular}{|l|l|}
\hline $\begin{array}{l}\text { Oliosi } \\
(2016)\end{array}$ & Não encontrado \\
\hline $\begin{array}{l}\text { Beretta, } \\
\text { Oliveira } \\
\text { Vilela } \\
\text { (2or6) }\end{array}$ & Não encontrado \\
\hline $\begin{array}{l}\text { Watanabe, } \\
\text { Moreira, } \\
\text { Lima \& } \\
\text { Lima } \\
\text { (2or6) }\end{array}$ & Não encontrado \\
\hline
\end{tabular}

Fonte: A pesquisadora.

Na produção de Oliosi (2016), a palavra jogo no corpo do texto não foi encontrada. Sendo que identificamos que a produção se dá a palavra brincar. Beretta, Oliveira Vilela (2016), Watanabe, Moreira, Lima \&Lima (2016) não foi localizada a palavra jogo.

Para o aluno, o jogo favorece a construção de novas descobertas, desenvolve e enriquece sua personalidade e simboliza um instrumento pedagógico que leva ao professor a condição de condutor, estimulador e avaliador da aprendizagem. Assim, o objetivo dos jogos é auxiliar o processo de aquisição de conhecimento do educando a partir de recursos proporcionados de forma a mostrar uma prática pautada nos jogos, para que os educadores possam dinamizar o ensino. $\mathrm{O}$ jogo mostrou-se uma ferramenta bastante importante para a aquisição do saber, por ser um recurso estimulante e inovador aos alunos, o mesmo proporciona o interesse do aluno pela sua própria aprendizagem através dos jogos.

Esses ajudam a criar um entusiasmo sobre o conteúdo a ser trabalhado a fim de considerar os interesses e as motivações dos educandos em expressar-se, agir e interagir nas atividades lúdicas realizadas na sala de aula. Além de proporcionar a criança os limites necessários no jogo, através de suas normas e regras. Fazendo com que o aluno adquira a capacidade de respeitar as regras do jogo, a vez do próximo, o saber ganhar ou perder entre outros. 


\subsection{A IMPORTÂNCIA DAS BRINCADEIRAS NAS PRÁTICAS PEDAGÓGICAS PARA O PROCESSO DE ENSINO E APRENDIZADO NA EDUCAÇÃO INFANTIL.}

Este estudo tem como atribuição abranger a importância das brincadeiras e os métodos utilizados nas práticas pedagógicas curriculares da Educação Infantil, para o processo de ensino e aprendizado, de acordo com os artigos encontrados no portal de periódicos da CAPES, na qual os mesmos vêm sendo destacado no quadro 4 .

Quadro 4-A importância das brincadeiras nas práticas pedagógicas

\begin{tabular}{|c|l|}
\hline Autor & \multicolumn{1}{|c|}{ Artigo } \\
\hline $\begin{array}{c}\text { Cambraia, } \\
\text { Lobato, } \\
\text { Nascimento } \\
(2018)\end{array}$ & $\begin{array}{l}\text { Através da brincadeira que a criança resgata a cultura infantil das gerações } \\
\text { anteriores mantendo a tradição e a universalização do brincar, " muitas } \\
\text { brincadeiras preservam sua estrutura inicial, outras modificam-se, } \\
\text { recebendo novos conteúdos" KISHIMOTO (2oir, p.43), mas sempre } \\
\text { mantém a essência da brincadeira, mesmo mudando uma palavra ou outra } \\
\text { de acordo com a cultura do local. (p,87) }\end{array}$ \\
\hline $\begin{array}{c}\text { Oliosi } \\
\text { (2016) }\end{array}$ & $\begin{array}{l}\text { De acordo com a fala de uma professora entrevistada, Através da } \\
\text { brincadeira desenvolve tanto o lado social quanto o pedagógico, os limites } \\
\text { e regras, de forma lúdica. (p,I3I8) }\end{array}$ \\
\hline $\begin{array}{c}\text { Beretta, } \\
\text { Oliveira } \\
\text { Vilela } \\
(2016)\end{array}$ & $\begin{array}{l}\text { As brincadeiras pressupõem uma aprendizagem sócio-cultural, pois além } \\
\text { de construir e reconstruir conhecimentos, as atividades lúdicas e artísticas } \\
\text { tornam os encontros mais interessantes, dinâmicos e criativos } \\
\text { (BEHLING; ISLAS, 20I4). (p,I4I) }\end{array}$ \\
\hline $\begin{array}{c}\text { Watanabe, } \\
\text { Moreira, } \\
\text { Lima \& } \\
\text { Lima } \\
(2016)\end{array}$ & Não encontrado \\
\hline
\end{tabular}

Fonte: A pesquisadora.

Nas produções de Cambraia, Lobato, Nascimento (2018) Conforme apontado por KISHIMOTO (2or p.43) "a brincadeira de faz de conta é também conhecida como simbólica, como representação de papeis ou sócio-dramática, uma vez que deixa evidente a presença da situação imaginaria”. A brincadeira imaginaria de uma criança permiti a ela fazer uma viagem onde ela absorve uma visão de mundo, fazendo com que o seu cognitivo de desenvolva com mais agilidade.

Para tanto, é relevante explorar o conhecimento prévio das crianças, de forma contextualizada, com os conteúdos programáticos que se quer trabalhar como processo teórico- metodológico em sala de aula. Buscará evidenciar os aspectos positivos e possíveis 
contribuições para a aprendizagem e o desenvolvimento integral da criança. Contribuirá também para construção do conhecimento cientifico e reafirmação da relevância do tema em estudo.

\footnotetext{
Cabe à escola fazer a criança avançar na sua compreensão do mundo a partir do desenvolvimento já consolidado, tendo como etapas posteriores, ainda não alcançadas. O papel do/a professor/a consiste em intervir na zona de desenvolvimento proximal ou potencial dos/as alunos/as, provocando avanços que não ocorreriam espontaneamente. (CRAIDY; KAERCHER, 20oI, p. 30).
}

A brincadeira não é um mero passatempo, ela ajuda no desenvolvimento das crianças, promovendo processos de socialização e descoberta do mundo. Para o aluno, o jogo ajuda-o a construir suas novas descobertas, desenvolve e enriquece sua personalidade e simboliza um instrumento pedagógico que leva ao professor a condição de condutor, estimulador e avaliador da aprendizagem. No texto de Watanabe, Moreira, Lima \&Lima (2016) não foi localizada a palavra brincadeira.

\section{${ }_{4}$ CONSIDERAÇÕES FINAIS}

Desde a Antiguidade, os jogos e brincadeiras sempre tiveram um forte vínculo com o processo de aprendizagem, como uma forma de tornar a aquisição do conhecimento mais fácil e prazeroso. Com o passar do tempo e as inovações tecnológicas, o brincar foi aos poucos sendo cada vez menos utilizado com propósito de fortalecer o ensino e fornecer aos pedagogos instrumentos e estratégias que pudessem ser inseridas em sala de aula sem que fosse tirado o foco da real significação do ato de brincar em si.

Esses paradigmas vêm aos poucos se modificando quando se percebeu que o desenvolvimento físico e psíquico da criança necessita dessa fase de transição no período infantil para que possa estar apta a seguir com seus processos cognitivos de maneira saudável e independentes de recursos tecnológicos.

Não é uma tarefa fácil diante da atração que a tecnologia exerce sobre todos, inclusive crianças, então o pedagogo tem que se planejar de forma e rever seus conceitos pedagógicos, seus fazer cotidiano, suas metodologias para trazer à sala de aula brincadeiras e jogos significativos e ao mesmo tempo atrativos para as crianças, além de ter a preocupação com o lado de formação holística, de preparação para o mundo. 
É no ambiente lúdico que a criança assume realmente seu protagonismo, pois é natural para a fase que vive. Isso demanda a participação familiar de forma efetiva, pois de nada adianta o pedagogo e a equipe escolar planejar e executar um programa de ensino aprendizagem que seja inclusivo através dos jogos e brincadeiras, se ao chegar em casa a criança vai ter como único foco os jogos eletrônicos, dos quais ela nada vai extrair para sua formação como ser humano crítico e participativo na comunidade que o rodeia.

A relevância do papel dos jogos e brincadeiras que foi o foco central de pesquisa, levantamento de dados e análise, é sem dúvida um caminho desafiador para uma faixa etária que se adequa com relativa facilidade às novidades que lhes são apresentadas. Portanto, o que se pretendeu ressaltar e ratificar através dessa pesquisa é que além de viável e necessário, é essencial que a criança tenha o contato com jogos e brincadeiras instigantes, que lhes permita usar seus conhecimentos prévios, enquanto o pedagogo vai inserindo os conteúdos e conhecimentos sistematizados, sem que haja prejuízo de nenhum dos lados.

Ao finalizar este trabalho, a autora assevera que seus objetivos foram cumpridos e que as premissas que a fizeram escolher esse tema reiteradamente comprovadas através dos autores que embasaram a pesquisa. Ainda resta muito trabalho, mas os desafios renovam o modo de ver a educação e seu vínculo com o brincar.

\section{REFERÊNCIAS}

ALMEIDA, P. N. de. Educação lúdica. Técnicas e jogos pedagógicos. São Paulo. Loyola, 2013.

ANTUNES, R. O Lúdico e a Aprendizagem. São Paulo. Versus. 2014.

BRASIL, Ministério da Educação e do Desporto. Secretaria de Educação Fundamental. Referencial curricular nacional para a educação infantil. Brasília, DF: MEC/SEF, 1998.

BRASIL. Ministério da Educação. Base Nacional Comum Curricular. 2018. http://basenacionalcomum.mec.gov.br/abase/ Acesso: 16/12/2020 
DANIEL CORTES BERETTA, JUCIENE SILVA OLIVEIRA, DANIELA COSTA VILELA. A extensão universitária e a ludicidade na Educação Infantil contra crueldade animal e violência interpessoal (2016). Revista Brasileira de Extensão Universitária, v.7, n.2, p. 139-I44 jul./dez. 2016. Centro Universitário de Mineiros (UNIFIMES), Brasil

DENISE WATANABE, TONY APARECIDO MOREIRA, JOSÉ MILTON DE LIMA, MÁRCIA REGINA CANHOTO DE LIMA. A interatividade como ferramenta da ludicidade em busca de caminhos e sentidos na Educação Infantil (2016). Revista Colloquium Humanarum, Presidente Prudente, v.13, n.3, p.18-27 jul./set 2016.

ELIETE DA SILVA CAMBRAIA, NILCE LÉA LOBATO, RÔMULO PEREIRA NASCIMENTO. A ludicidade na alfabetização matemática no âmbito da Educação Infantil (2018). Revista de Educação Matemática, Dourados - MS - Número v,I, pp.76 - 9I, (2008).

Faculdade Ieducare - FIED. Guia de Normalização de Trabalho Acadêmicos da Faculdade Ieducare - FIED. Tianguá-Ceará. 2020.

KISHIMOTO, T. M. (Org.) Jogo, brinquedo, brincadeira e a educação. São Paulo: Cortez. 2014.

LAKATOS, Eva Maria e Marconi Marina de Andrade, técnica de pesquisa: planejamento e execução de pesquisa, amostragem e técnicas de pesquisa, elaboração, análise e interpretação de dados. 3, ed. São Paulo: Atlas, 1996.

Ministério da Educação. Secretaria de Educação Básica. Diretrizes Curriculares Nacionais para a Educação Infantil. Brasília. 2009 https://quizlet.com/br/453152108/dcnei-diretrizescurriculares-nacionais-para-a-educacao-infantil-flash-cards/ Acesso: 16/12/2020

MARKONIS \& LAKATOS. Metodologia do Trabalho Científico. São Paulo. Vozes. 2015. 
MINAYO, M.C. de S. O desafio do conhecimento: Pesquisa Qualitativa em Saúde. São Paulo: Hucitec-Abrasco. 2017.

OLIVEIRA, S. S. G. de, DIAS, M. da G.B. E ROAZZI, A. O Lúdico e suas implicações nas estratégias de regulação das emoções. São Paulo. Sprint, 2016.

RIBEIRO, N. M. A evolução da comunicação na criança. Belo Horizonte. Imprensa Oficial, 2016.

ROGERS, V. L. B. Promovendo o desenvolvimento do faz-de-conta na educação. Rio de Janeiro. Sprit, 2015.

SOLÈ, I. Bases Psicopedagógicas de La practica educativa. Barcelona, Horsori, 2013.

SIMONE RIBEIRO OLIOSI. A ludicidade no contexto das práticas pedagógicas na Educação Infantil de o a 3 anos (2016). Revista Even. Pedagoóg. Número Regular: Experiência em Educação do Campo: perspectivas e práticas pedagógicas, Sinop, v.7, n. 3 (20.ed.), p. 1307-1320, ago./dez. 2016.

VELASCO, C.G. Habilitações e Reabilitações Psicomotoras. São Paulo. Harbra, 2015.

WINNICOTT, D. W. O brincar e a realidade. Rio de Janeiro. Imago, 2016. 